\title{
An explanation of orthogonal S-R compatibility effects that vary with hand or response position: The end-state comfort hypothesis
}

\author{
YVONNE LIPPA \\ Max Planck Institute for Psychological Research, Munich, Germany \\ and Indiana University, Bloomington, Indiana \\ and \\ JOS J. ADAM \\ Maastricht University, Maastricht, The Netherlands
}

\begin{abstract}
This study presents an explanation of orthogonal stimulus-response compatibility (SRC) effects that vary with hand or response location: the end-state comfort hypothesis. It posits that responses are spatially transformed and cognitively mapped onto the stimulus dimension according to relative hand posture, thereby mediating the pattern of facilitation and interference in response selection. In the first three experiments, we investigated the eccentricity effect, finding that responses by the left hand in left hemispace are faster with up-left/down-right mapping while responses by the right hand in right hemispace are faster with up-right/down-left mapping (Michaels \& Schilder, 1991, Experiment 1). The endstate comfort hypothesis correctly predicted that the eccentricity effect occurred irrespective of the relative position of the stimulus and response device in the sagittal plane (Experiments 1 and 2), and that it reversed when the stimulus-response set was reversed, regardless of the relative position of the stimulus and response device in the fronto-parallel plane (Experiments 2 and 3). Experiment 4 shows a new orthogonal SRC effect that was predicted by the end-state comfort hypothesis. Our results are inconsistent with other explanations, such as the virtual-lines hypothesis and the salient-features hypothesis.
\end{abstract}

Since the seminal work of Fitts and Deininger (1954), the phenomenon of spatial stimulus-response compatibility (SRC) has received much theoretical and experimental attention (e.g., Hommel \& Prinz, 1997; Proctor \& Reeve, 1990). A classic demonstration of this effect in a choice reaction task in which left and right stimulus locations and left and right response locations are used is that responses are faster and less error prone when stimuli and responses spatially correspond than when they do not spatially correspond (Leonard, 1959). Usually, spatial SRC effects are quite robust and occur under a wide variety of conditions. For example, they have been reported when spatial position is a task-irrelevant stimulus feature (Simon \& Rudell, 1967), when stimuli and responses are spatially congruent only with respect to their cognitive representations (Ridderinkhof, 1993), and when spatial

\footnotetext{
The authors thank Fiorello Banci and Karl-Heinz Honsberg for constructing the stimulus and response device for the first three experiments, and Poldi-Eva Leo and Sabine Rau for conducting these experiments. Further, we thank Robert Goldstone and Richard Shiffrin for providing facilities to run the fourth experiment, Robert Proctor, Claire Michaels, Steven Yantis, and an anonymous reviewer for their helpful comments on a previous version of the article, and Robert Kennison for checking and improving the English. Correspondence should be addressed to Y. Lippa, Department of Psychology, University of California, Santa Barbara, CA 93106-9660 (e-mail: lippa@ psych.ucsb.edu).
}

stimuli and responses are coded in different frames of reference (Brebner, Shephard, \& Cairney, 1972; Hommel \& Lippa, 1995).

Current theories of stimulus-response (S-R) compatibility-like the dimensional overlap model proposed by Kornblum and colleagues (Kornblum, Hasbroucq, \& Osman, 1990; Kornblum \& Lee, 1995) or the action concept model suggested by Hommel (1997) — explain SRC effects by assuming that an upcoming stimulus triggers its feature-corresponding response. For example, a left stimulus triggers a left response and a right stimulus triggers a right response. In the compatible condition (i.e., when stimuli and responses correspond), this results in faster selection of the correct responses. In the incompatible condition (i.e., when stimuli and response do not correspond), however, the stimulus always activates the incorrect response. This results either in an error or in longer reaction times (RTs), depending on whether the wrong response can be suppressed or not and whether the correct response is initiated.

This explanation of a stimulus-driven response activation implies that SRC effects occur only when stimulus and response dimensionally overlap. That is, a stimulus can activate its feature-corresponding response only if it shares one or more features with the response. Yet, SRC effects have sometimes been reported when stimulus and response do not have a common feature. That is, $\mathrm{S}-\mathrm{R}$ 
mapping preferences have been observed when the stimulus and response dimensions are physically orthogonal to each other (orthogonal SRC effects). This poses a problem for current theories of S-R compatibility.

Basically, two sorts of orthogonal SRC effects are known. On the one hand, there is an overall advantage of up-right/down-left mapping. Regardless of whether the response is manual or vocal, unimanual or bimanual, and whether the stimuli are spatial or symbolic, assigning top stimuli to right responses and bottom stimuli to left responses is easier than applying the reversed up-left/ down-right mapping (Adam, Boon, Paas, \& Umiltà, 1998; Weeks \& Proctor, 1990). On the other hand, there are $\mathrm{S}-\mathrm{R}$ mapping preferences that vary with the responding hand or with the position of the response device (Bauer \& Miller, 1982; Michaels \& Schilder, 1991; Weeks, Proctor, \& Beyak, 1995). The present study deals only with the latter SRC effects and aims to provide an explanation that conforms with the dimensional overlap criterion put forth by current theories of S-R compatibility.

Generally, we propose that despite physical orthogonality between stimulus and response, the associated mental representations can overlap because responses are coded on the same dimension as the stimuli. This hypothesis was pursued by Lippa (1996) in her work on the referentialcoding hypothesis. In the next section we describe this hypothesis and the relevant data in more detail. Although the referential-coding hypothesis proved to account for a variety of effects, its explanatory scope is limited. It struggles, in particular, with accounting for the influence of eccentric response locations in orthogonal SRC effects (the eccentricity effect), reported by Michaels and Schilder (1991, Experiment 1).

The purpose of the present study was to test the endstate comfort hypothesis, an account that encompasses the explanatory scope of the referential-coding hypothesis, provides an explanation for the eccentricity effect, and also predicts new orthogonal SRC effects. In addition, two alternative explanations to the end-state comfort hypothesis are discussed, namely the virtual-lines hypothesis and the salient-features hypothesis. We report four experiments that test predictions of the three accounts, with the result that the end-state comfort hypothesis best explains the data.

\section{The Referential-Coding Hypothesis for Orthogonal SRC Effects That Vary With Hand}

A classic study on orthogonal SRC effects was conducted by Bauer and Miller (1982). The left panel of Figure 1 illustrates the basic experimental conditions as they were replicated by Lippa (1996, Experiments 1 and 4). Lippa combined vertical and horizontal S-R dimensions. One subject group responded to left and right stimuli by pressing top and bottom keys (top pictures of panel), and another group responded to top and bottom stimuli by pressing left and right keys (bottom pictures of left panel). In each condition, two mapping rules were employed. In one group, half the subjects responded with the left key for top stimuli and with the right key for bottom stimuli, while the other subjects received the reversed S-R mapping. In the other group, half the subjects responded with the top key for left stimuli and with the bottom key for right stimuli, while the other subjects received the reversed $\mathrm{S}-\mathrm{R}$ mapping. In addition to the mapping rule, the hand used to respond was manipulated. Each subject responded with the left hand (i.e., left index finger) in one block of trials, and the right hand (i.e., right index finger) in another. The results of Lippa demonstrated SRC effects that depended on which hand was used and which S-R set was used. Figure 1 (left panel) shows the preferred S-R assignments in each condition. It turned out that with horizontally oriented stimuli and vertically oriented responses, left-hand responding was fastest with the upleft/down-right mapping rule and right-hand responding was fastest with the up-right/down-left mapping rule. When the stimuli were presented in the vertical orientation and the responses were presented in the horizontal orientation, left-hand responding was fastest with the upright/down-left mapping rule, while right-hand responding was fastest with the up-left/down-right mapping rule.

These results demonstrate that SRC effects also occur in the absence of physical correspondence between stimuli and responses - when stimuli and responses vary on physically different dimensions. Such results run counter to the predictions of a stimulus-driven response activation account and pose a problem for current S-R compatibility theories. Lippa (1996) suggested a solution to this problem by arguing that despite physical orthogonality, stimuli and responses are cognitively coded on the same dimension and, therefore, meet the criterion of feature correspondence. Specifically, a referential-coding hypothesis was proposed, assuming that responses in the previously described experiments were not coded in reference to the subject's sagittal body midline, but rather in reference to the responding hand (i.e., the fingertip-to-wrist axis) held at an angle to the sagittal body midline. For example, in the left-hand condition depicted in the top left panel of Figure 1, the location of the top response key is coded as left because it is located to the left of the hand, and the location of the bottom key is coded as right because it is located to the right of the hand. This mapping of up-left/ down-right yields a perfect spatial correspondence between the coded stimuli and coded responses and, therefore, proves to be compatible. Right-hand responding, in turn, results in the opposite response coding because top maps on right and bottom maps on left. Therefore, the reversed S-R assignment (i.e., the up-right/ down-left mapping) is preferred.

This referential-coding explanation is also applicable to the effect illustrated in the bottom left panel of Figure 1 (see, e.g., Bauer \& Miller, 1982, Experiment 3; Lippa, 1996, Experiment 4) as well as to other orthogonal SRC effects reported in the literature (for details, see Lippa, 1996). For example, it accounts for results obtained with toggle switches (Michaels, 1989, Experiment 2; Weeks 


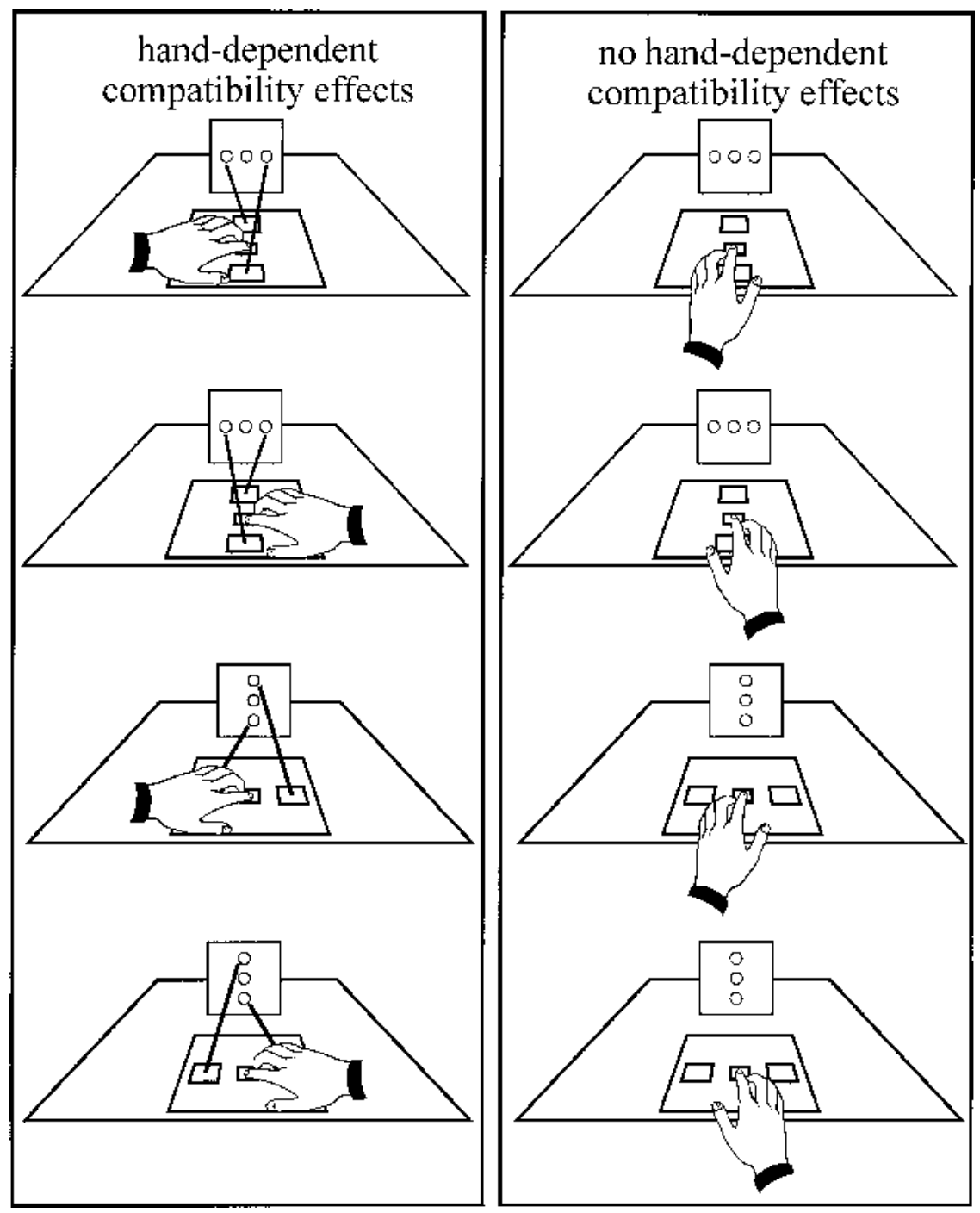

Figure 1. Illustrations of the experimental settings used in Lippa's (1996) Experiments 1, 2,4 , and 5, with the responding hand held at an angle to (left panel) or in line with (right panel) the sagittal body midline. Lines connecting stimulus $(S)$ and response ( $R$ ) locations indicate the preferred $S-R$ mapping. Absence of lines indicates that neither hand prefers one mapping over the other mapping.

et al., 1995, Experiment 1), with two-finger choice reactions (Ehrenstein, Schroeder-Heister, \& Heister, 1989), and with stimuli varying on two spatial dimensions (Cotton, Tzeng, \& Hardyck, 1977, Experiment 2; 1980, Experiment 1). In addition, it correctly predicts the conditions in which hand-dependent orthogonal SRC effects disappear. As shown in the right panel of Figure 1, they disappear when the hand is held in line with the sagittal body midline - that is, when hand posture evokes a response coding that is spatially orthogonal to the stimulus dimension (for details, see Lippa, 1996). Overall, the referential-coding hypothesis proved to be a powerful and consistent explanation for orthogonal SRC effects that vary with hand. However, Michaels and Schilder (1991,
Experiment 1) found a compatibility effect that questions the general applicability of the referential-coding hypothesis. In the following section, this effect is described and a more general account for orthogonal SRC effects is presented, namely the end-state comfort hypothesis.

\section{The End-State Comfort Hypothesis of Orthogonal SRC Effects That}

\section{Vary With Hand Or Response Position}

In their first experiment, Michaels and Schilder (1991) closely replicated Bauer and Miller's (1982) third experiment (see Figure 1, bottom left panel). Michaels and Schilder had subjects assign left and right responses to top and bottom stimuli. Yet, in addition to responding di- 
rectly in front of their body, subjects performed responses at eccentric locations. They responded with their ipsilateral hand on a response device located to the left and right of the body midline (see Figure 2, top left panel). In a preceding study, Michaels (1989, Experiment 1) used toggle switches as a response device, which allowed for several hand postures to be taken. The critical variable in Michaels and Schilder's study was that they used a switch appara- tus that held the hand and index finger in place in such a way that only left-right deflections perpendicular to the subject's sagittal body midline could be performed. Thus, in reference to the fingertip-to-wrist axis, responses should have been coded as left and right and represented orthogonally to the stimulus dimension. The referential-coding hypothesis therefore predicts that no hand-dependent compatibility effects would occur. But this was not the
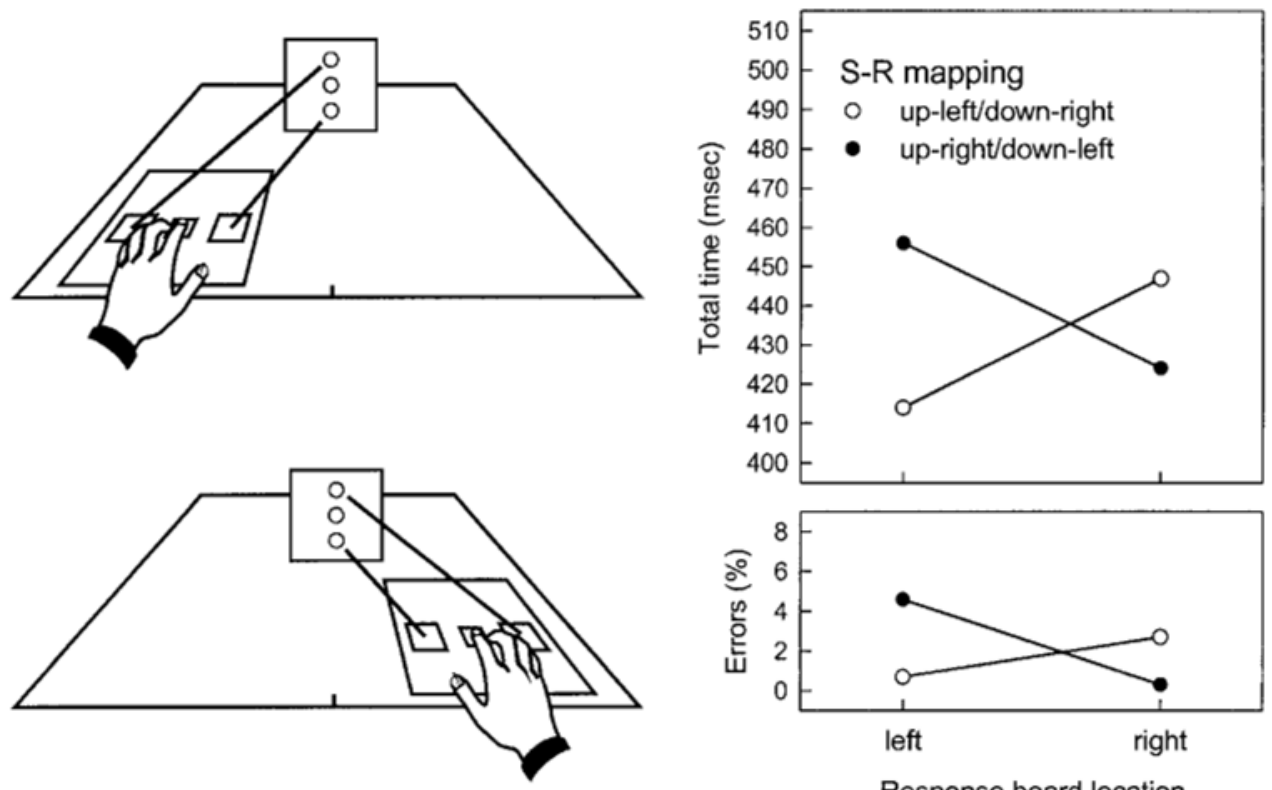

Response board location
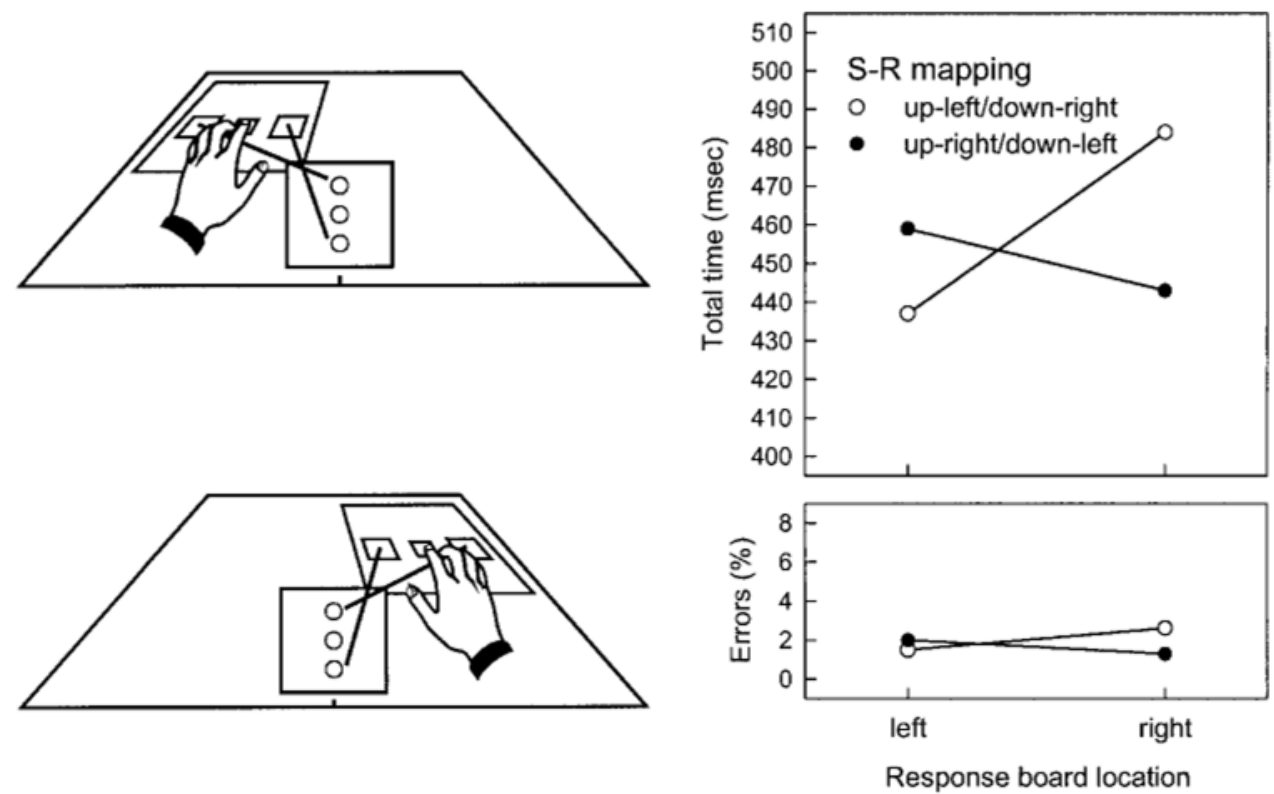

Figure 2. Left panels: The stimulus-response (S-R) arrangements investigated in Experiment 1, separately for the left and right response board location and the response board located in front of or behind the stimulus panel. Lines connecting stimulus and response locations indicate the preferred $S-R$ mapping. Right panels: The eccentricity effect obtained in Experiment 1, separately for the response board located in front of or behind the stimulus panel. Total times and errors are presented as a function of S-R mapping and response board location. 
case. Rather, Michaels and Schilder found that left-hand responding in left hemispace was fastest with an up-left/ down-right mapping and right-hand responding in right hemispace was fastest with an up-right/down-left mapping (see Figure 2, top right panel). In the following sections we refer to this data pattern as the eccentricity effect.

We assume that the eccentricity effect occurs because orthogonal S-R dimensions are mentally aligned by spatial transformations (see, e.g., Proctor, Reeve, Weeks, Campbell, \& Dornier, 1997). Like the referential-coding hypothesis, the end-state comfort hypothesis posits that hand posture causes a coding of the response dimension that matches the coding of the stimulus dimension. However, according to the end-state comfort hypothesis, hand posture does not effectuate this alignment by providing a frame of reference for responses separate from the frame of reference in which the stimuli are coded. Rather, it assumes that hand posture evokes spatial transformation processes that cognitively map the responses on the stimulus dimension in the same frame of reference, that of the sagittal body midline.

Consider the eccentricity design as depicted in the top left panel of Figure 2. A person is facing a stimulus panel with vertically oriented light-emitting diodes (LEDs) and performs left and right movements on a response board that is located to the left or right of the person's midline. To spatially align stimuli and responses in reference to the sagittal body midline, it would be possible to think of the stimulus panel being tilted $90^{\circ}$. However, findings from mental rotation studies involving body parts suggest not that the stimulus is transformed, but that imagined spatial transformations refer to what is under a person's control-that is, one's own body movements and actions. Cooper and Shepard (1975) and Parsons (1987a, 1987b) found that when comparing imagined body parts with presented body parts, people imagine moving their own body part to the orientation of the stimulus, rather than imagining moving the stimulus to the orientation of their own body part. Thus, in experimental settings investigating the eccentricity effect, it is likely that the response dimension - that is, the hand and the response board rather than the stimulus dimension-is subject to a spatial transformation. Accordingly, we assume that stimuli and responses match on the vertical dimension.

The spatial transformation of the response dimension can be achieved by mentally rotating the response board clockwise or counterclockwise. We assume that the rotation direction of the response board is determined by the rotation preference of the responding hand. Specifically, the board is mentally rotated in the direction that yields the most comfortable end posture for the hand. The importance of end-state comfort in constraining motor behavior has been demonstrated in studies on grasping. For example, if subjects are asked to grasp an object and turn it upside down, they start with an awkward grip to ensure that in the final position the arm and hand will be comfortable (Rosenbaum \& Jorgensen, 1992; Rosenbaum et al., 1990). Comfort in end-state posture has also been shown to determine pointing accuracy. Rossetti, Meckler, and Prablanc (1994) found that pointing accuracy was enhanced for comfortable postures and degraded for uncomfortable postures when subjects used extreme joint positions. Consistent with results of mental rotation studies, we assume that principles and constraints determining real body movements also determine imagined body movements. For example, it has been shown that the time required to judge whether a picture of a hand depicts the left or right hand increases as the difficulty to achieve the hand's position increases (Cooper \& Shepard, 1975; Parsons, 1994; Sekiyama, 1982).

When the principle of end-state comfort is applied to the experimental setting of the eccentricity effect, inward movements of both hands are predicted. The positioning of the hands at eccentric locations causes hand (and arm) movements toward the body to be more efficient and comfortable than hand (and arm) movements away from the body (see, e.g., Bradshaw, Bradshaw, \& Nettleton, 1990). This reasoning leads to the explanation of the eccentricity effect. Left-hand responding evokes a clockwise rotation of the left response board. Thus, the left key becomes the top key and the right key the bottom key, thereby favoring the up-left/down-right mapping over the up-right/down-left mapping. Right-hand responding, in turn, evokes a counterclockwise rotation, mapping "left" on "down" and "right" on "up," thereby favoring the up-right/down-left mapping over the up-left/ down-right mapping. ${ }^{1}$

The end-state comfort hypothesis also accounts for Weeks et al.'s (1995, Experiment 1) finding that the eccentricity effect occurred irrespective of whether the ipsi- or contralateral hand was used. When one hand crosses the body midline and operates in the contralateral hemispace, the most comfortable and perhaps the only possible hand and arm posture that can be maintained over time is one in which fingertip, wrist, and forearm are aligned. Given this posture, it was most comfortable to move the hand and arm away from the body, suggesting a clockwise rotation of a left-side located response board and a counterclockwise rotation of a right-side located response board. This rotation pattern was the same as in the original design of the eccentricity effect and, therefore, the eccentricity effect remained unaffected.

Besides explaining the eccentricity effect, the end-state comfort hypothesis also accounts for the orthogonal SRC effects reported and reviewed by Lippa (1996). The conditions depicted in Figure 1 serve again as an example. If the response board is located directly in front of the body and the hand is held at an angle to the sagittal body midline (see Figure 1, left panel), for either hand it is most comfortable to rotate outward. Thus, left-hand responding should evoke a counterclockwise rotation of the response board, causing an up-left/down-right mapping preference for left-right stimuli and top-bottom responses and an up-right/down-left mapping preference for top-bottom stimuli and left-right responses. Righthand responding, in turn, should evoke a clockwise rota- 
tion of the response board and, therefore, reverse the compatibility effects. Alternatively, if the hand is held in line with the sagittal body midline (Figure 1, right panel), hand movements are much more restricted. In fact, to achieve this hand posture, Lippa instructed subjects to back off a bit from the response board so that the hand as well as the forearm operated in front of the body. This made it easier to perform forward and backward movements, but more difficult (especially, in case of top responses) to deviate from the fingertip-to-wrist axis. In this case, neither hand should have rotation preferences, thus causing a response coding orthogonal to the stimulus dimension that prevents hand-dependent compatibility effects to occur.

\section{Alternative Explanations for the Eccentricity Effect}

The end-state comfort hypothesis encompasses the explanatory scope of the referential-coding hypothesis and also provides an explanation for the eccentricity effect. However, for the eccentricity effect, there are at least two other explanations. Weeks et al. (1995) offered a salientfeatures hypothesis. This explanation is based on the salient-features coding principle, which states that "the stimulus and response sets are coded in terms of the salient features of each, with response determination occurring most rapidly when the salient features of the respective sets correspond" (Proctor \& Reeve, 1986, p. 278). Consistent with previous results (e.g., Chase \& Clark, 1971), Weeks et al. assumed that, for the vertical dimension, "up" is more salient than "down." For the horizontal dimension, they argued that saliency depends on response location. When responding takes place in left hemispace, "left" is salient, and when responding takes place in right hemispace, "right" is salient. Thus, according to the salient-features explanation, the eccentricity effect occurs because, with changing response locations, the $\mathrm{S}-\mathrm{R}$ features that match change. When the response board is in left hemispace, "left" is salient and "right" is nonsalient, matching "up" and "down," respectively (upleft/down-right mapping preference). When the response board is in right hemispace, "right" is salient and "left" is nonsalient, causing an up-right/down-left mapping preference. Weeks et al. found evidence for the salientfeatures hypothesis. In their first experiment, they dissociated the influences of hand identity and response location by having subjects respond with each hand at eccentric locations in both hemispaces. As described earlier, it turned out that, regardless of which hand was used, when responding took place in left hemispace, the up-left/ down-right mapping yielded better performance, and when responding took place in right hemispace, the up-right/down-left mapping yielded better performance. The influence of response location was additionally demonstrated by finding the same pattern even when response location was coded as left and right only in refer- ence to another response device (Weeks et al., 1995, Experiment 2).

Another explanation for the eccentricity effect is the virtual-lines hypothesis. This explanation assumes that subjects visualize the orthogonal S-R mapping by imagining virtual lines or vectors connecting the stimulus and response locations. This idea is consistent with evidence showing that, in addition to a body-centered coding system of spatial relations, humans also use an environmentcentered system that codes information about interobject relations in terms of geometric vectors connecting proximate objects (Easton \& Sholl, 1995). When this notion is applied to the experimental design of the eccentricity effect, the compatible conditions would be represented by parallel, uncrossed lines (Figure 2, top left panel). That is, stimulus and response locations are connected with parallel lines when up-left/down-right mapping takes place on the left response board, or when up-right/downleft mapping takes place on the right response board. The incompatible conditions, in turn, would be represented by crossed lines (i.e., up-right/down-left mapping on the left response board, and up-left/down-right mapping on the right response board). It is assumed that the crossing of interobject vectors forms a less direct, more ambiguous configuration than the uncrossed vectors and therefore results in worse performance. Thus, according to the virtual-lines hypothesis, the eccentricity effect occurs because the imagined crossing lines in the incompatible conditions create interference, whereas the parallel, noncrossing lines in the compatible condition do not.

Subsequently, four experiments are reported that were conducted to test the predictions of the end-state comfort hypothesis. In the first three experiments, the eccentricity effect was investigated, contrasting the end-state comfort hypothesis with the virtual-lines hypothesis (Experiments 1 and 2) and versions of the salient-features hypothesis (Experiments 2 and 3). In Experiment 4, we tested experimental conditions by which the end-state comfort hypothesis predicts a new orthogonal SRC effect.

\section{EXPERIMENT 1}

In contrast to most previous studies, in the present experiment, switches were not used as a response device, but rather keys that had to be actuated with the index finger. In order to demonstrate that the eccentricity effect also emerges with the keys, we included a condition that followed the original S-R arrangement- that is, top and bottom stimuli combined with left and right responses to be performed on a response board located to the left or right of the subject's sagittal body midline (see Figure 2, top left panel).

A second condition was designed to test the predictions of the virtual-lines hypothesis by dissociating the variables "S-R mapping rule" and "crossed versus uncrossed lines." The crucial manipulation was to vary the position 
of the response board relative to the position of the stimulus panel with respect to the sagittal plane. In the standard situation, the response board is closer to the body than is the stimulus panel (Figure 2, top left panel). This creates the correspondence between compatible mappings and parallel lines, and between incompatible mappings and crossed lines. If the response board is moved away from the body so that it is positioned behind the stimulus panel, the relationship between $\mathrm{S}-\mathrm{R}$ mapping and virtual lines is reversed (Figure 2, bottom left panel). That is, the crossed lines are now associated with the compatible mappings (of the standard situation) and the parallel lines with the incompatible mappings (of the standard situation). Thus, if crossed versus uncrossed virtual lines is critical in determining the preferred mapping rule, then the manipulation of moving the response board behind the stimulus panel should reverse the eccentricity effect; left-hand responding in left hemispace should be fastest with up-right/down-left mapping and right-hand responding in right hemispace should be fastest with upleft/down-right mapping.

In contrast to the virtual-lines hypothesis, the salientfeatures hypothesis and the end-state comfort hypothesis predict no difference between the two experimental conditions. Moving the response board in the sagittal plane changes neither its horizontal position with respect to the body's midline nor the direction of the rotation that gives the most comfortable hand posture. Therefore, the salientfeatures hypothesis and the end-state comfort hypothesis both predict the original eccentricity effect regardless of the position of the response board in the sagittal plane; left-hand responding in left hemispace should be fastest with up-left/down-right mapping, and right-hand responding in right hemispace should be fastest with upright/down-left mapping.

\section{Method}

Subjects. Eleven female and 5 male subjects (15 right-handed and 1 ambidextrous by self-report) were paid to participate in the experiment. Their mean age was 24.9 (range $=21-37$ ). All subjects had normal or corrected-to-normal acuity.

Apparatus and S-R set. Stimulus presentation and data acquisition were controlled by a Rhothron VME system. Two red LEDs located above and below a central green fixation LED $(1.5 \mathrm{~cm}$ center-to-center) served as stimuli. They were mounted on a wooden board $(16 \times 16 \mathrm{~cm})$ tilted approximately $45^{\circ}$ backward from the vertical axis. The distance between the central LED and the table was approximately $15 \mathrm{~cm}$.

Responses were made on a horizontal $31 \times 31 \mathrm{~cm}$ response board interfaced with the computer. Three square touch-sensitive metal plates mounted on the board served as response keys: A central home key $(2.5 \times 2.5 \mathrm{~cm})$ and two response keys $(3 \times 3 \mathrm{~cm})$ were located $2.7 \mathrm{~cm}$ (edge-to-edge) to the right and the left of the home key.

Procedure. Subjects were seated at the table facing the stimulus panel. Their sagittal body midline was in line with the central LED. The response board was $3 \mathrm{~cm}$ above table height and located $40 \mathrm{~cm}$ either to the left or the right of the subject on the table (measured from the home key's center to the subject's sagittal midline). The distance between the center of the home key and the fixation light was $43 \mathrm{~cm}$. Independent of the respective experimental condition, sub- jects were required to keep their responding hand at a straight angle to the fronto-parallel plane (i.e., to the line of the horizontally oriented response keys).

The variable $\mathrm{S}-\mathrm{R}$ arrangement was manipulated between subjects. For half the subjects, the distance between the center of the stimulus panel and the subject's frontal plane was approximately $55 \mathrm{~cm}$ and the response board was placed close to the front edge of the table. For the other subject group, the distance between the center of the stimulus panel and the subject's frontal plane was approximately $35 \mathrm{~cm}$. The response board was placed to the left or right side behind the stimulus panel, with the distance between the fixation light and the center of the home key kept at $43 \mathrm{~cm}$.

The subject's task was to move the index finger of the engaged hand from the home key and touch the left or right key in response to top or bottom stimuli. Each subject group completed four blocks. In the first two blocks, subjects used one of the two S-R mappings (e.g., up-left/down-right) and in the last two blocks, they used the other one (e.g., up-right/down-left). In the first and third blocks, the response board was placed on the one side of the subject, and in the second and fourth blocks, it was placed on the other side. At all times, subjects responded with the hand ipsilateral to the placement of the response board. The order of S-R mapping and response board location was balanced across subjects. Each block consisted of 90 trials: 10 practice trials and 80 test trials (40 for each stimulus location). To familiarize the subjects with the relevant S-R mapping rule, additional training was given. Ten practice trials were given before the first two blocks and 20 practice trials before the second two blocks.

Each trial began with the green fixation light flashing in the center of the stimulus panel. The light flashed until the subject touched the home key with the index finger of the responding hand. Next, the fixation light was lit constantly for $1 \mathrm{sec}$. Following a delay of $100 \mathrm{msec}$, either the top or bottom red light was presented. The stimulus remained visible until the subject responded or $1 \mathrm{sec}$ had passed (a missing trial). If a subject released the home key before stimulus onset, the trial was stopped and restarted with the presentation of the flashing fixation light. Auditory feedback (a beep) was given for error, missing $(0.6 \%)$, and anticipation trials (RT equal to or below $120 \mathrm{msec}: 0.6 \%$ ), which were then repeated at a random position in the remainder of the block.

\section{Results}

We collected data on three dependent variables: mean RT - the time interval between stimulus onset and movement onset; mean movement time (MT) - the time from movement onset to engagement of the response key; and percent of errors. Since the experimental situation allowed subjects to lift their finger before the decision process or movement programming was completed, the relevant SRC effects may be distributed over RT and MT data (for a discussion of issues in measuring compatibility effects with aimed movements, see Proctor \& Wang, 1997). Therefore, total times (TTs) - that is, the sum of RTs and MTs - were calculated and used as the primary dependent measure.

Analyses of variance (ANOVAs) were conducted on TT and error data, with S-R arrangement (response panel in front of and behind the stimulus panel) serving as a between-subjects variable, and S-R mapping (up-left/ down-right vs. up-right/down-left), response board location (left vs. right), and response location (left vs. right) serving as within-subjects variables. Mean RTs, MTs, TTs, and error rates are presented in Table 1. 
Table 1

Mean Reaction Time (RT), Mean Movement Time (MT), Mean Total Time (TT, in Milliseconds), and Mean Error Rates (in Percentages) in Experiment 1 as a Function of Stimulus-Response Arrangement, Response Board Location, and Stimulus and Response Location

\begin{tabular}{|c|c|c|c|c|c|c|c|c|}
\hline \multirow[b]{3}{*}{ Response Location } & \multicolumn{4}{|c|}{ Response Board in Front of the Stimulus Panel } & \multicolumn{4}{|c|}{ Response Board Behind the Stimulus Panel } \\
\hline & \multicolumn{2}{|c|}{$\begin{array}{c}\text { Response Board } \\
\text { on Left } \\
\text { Stimulus Location }\end{array}$} & \multicolumn{2}{|c|}{$\begin{array}{c}\begin{array}{c}\text { Response Board } \\
\text { on Right }\end{array} \\
\text { Stimulus Location } \\
\end{array}$} & \multicolumn{2}{|c|}{$\begin{array}{c}\begin{array}{c}\text { Response Board } \\
\text { on Left }\end{array} \\
\text { Stimulus Location } \\
\end{array}$} & \multicolumn{2}{|c|}{$\begin{array}{c}\text { Response Board } \\
\text { on Right } \\
\text { Stimulus Location }\end{array}$} \\
\hline & Up & Down & Up & Down & Up & Down & Up & Down \\
\hline \multicolumn{9}{|l|}{ Left } \\
\hline RT & 281 & 316 & 315 & 284 & 279 & 315 & 311 & 300 \\
\hline MT & 135 & 138 & 141 & 136 & 159 & 145 & 164 & 146 \\
\hline TT & 416 & 454 & 456 & 420 & 438 & 460 & 475 & 446 \\
\hline Errors & 0.0 & 2.4 & 4.9 & 0.0 & 2.4 & 1.7 & 3.6 & 0.6 \\
\hline \multicolumn{9}{|l|}{ Right } \\
\hline RT & 314 & 276 & 288 & 301 & 300 & 292 & 294 & 331 \\
\hline MT & 143 & 138 & 140 & 137 & 157 & 143 & 145 & 161 \\
\hline $\mathrm{TT}$ & 457 & 414 & 428 & 438 & 457 & 435 & 439 & 492 \\
\hline Errors & 2.9 & 1.4 & 0.6 & 4.3 & 2.3 & 0.6 & 1.9 & 1.5 \\
\hline
\end{tabular}

Total times. The mapping $\times$ response board location interaction was highly significant $[F(1,14)=46.80$, $\left.M S_{\mathrm{e}}=686.20, p<.001\right]$. Responding on the left response board was faster with the up-left/down-right mapping rule $(426 \mathrm{msec})$ than with the up-right/down-left mapping rule $(457 \mathrm{msec})\left[F(1,14)=10.32, M S_{\mathrm{e}}=\right.$ $1,567.42, p<.01]$. The reversed effect occurred for responding on the right response board (465 vs. $433 \mathrm{msec}$ for up-left/down-right and up-right/down-left mapping, respectively) $\left[F(1,14)=6.70, M S_{\mathrm{e}}=2,377.25\right.$, $p<.05]$. In addition, the mapping $\times$ response board location $\times$ response location $\times \mathrm{S}-\mathrm{R}$ arrangement interaction was reliable $\left[F(1,14)=6.78, M S_{\mathrm{e}}=133.81, p<\right.$ $.05]$. With the response board in front of the stimulus panel, the compatibility effect was larger for left $(37 \mathrm{msec})$ than for right $(27 \mathrm{msec})$ responses $\left[F(1,7)=2.00, M S_{\mathrm{e}}=\right.$ $180.54, p=.20]$. When the response board was behind the stimulus panel, the compatibility effect was larger for right $(38 \mathrm{msec})$ than for left $(26 \mathrm{msec})$ responses $\left[F(1,7)=6.39, M S_{\mathrm{e}}=87.08, p<.05\right]$. There is no ready explanation for this particular result.

Errors. The mapping $\times$ response board location interaction was reliable $\left[F(1,14)=18.52, M S_{\mathrm{e}}=7.08\right.$, $p<.01]$. Responding on the left response board produced fewer errors with the up-left/down-right mapping $(1.1 \%)$ than with the up-right/down-left mapping (2.3\%) $\left[F(1,14)=2.58, M S_{\mathrm{e}}=9.50, p=.131\right]$. The reversed effect occurred for responding on the right response board $(3.6 \%$ vs. $0.8 \%$ for up-left/down-right and up-right/down-left mapping, respectively) $[F(1,14)=$ $\left.15.70, M S_{\mathrm{e}}=8.04, p<.01\right]$. This interaction, however, was modulated by a higher order mapping $X$ response board location $\times \mathrm{S}-\mathrm{R}$ arrangement interaction $[F(1,14)=$ 5.57, $\left.M S_{\mathrm{e}}=7.08, p<.05\right]$. When the response board was in front of the stimulus panel, responding on a left response board produced fewer errors with up-left/downright mapping $(0.7 \%)$ than with up-right/down-left $(2.7 \%)$. The reverse was true for responding on the right response board ( $4.6 \%$ vs. $0.3 \%$ for up-left/down-right and up-right/down-left mapping, respectively). With the response board behind the stimulus panel, a significant difference between the two mappings occurred only when responding took place on the right response board (2.6\% and $1.3 \%$ for the up-left/down-right and up-right/ down-left mapping, respectively), whereas responding on a left response board yielded no difference $(1.5 \%$ and $2.0 \%$ for the up-left/down-right and up-right/down-left mapping, respectively).

\section{Discussion}

The results of Experiment 1 showed that the relative position of the stimulus panel and response board in the sagittal plane does not influence the direction of the eccentricity effect. That is, regardless of the position of the response board in the sagittal plane, left-hand responding on the left response board produced an up-left/down-right mapping advantage, whereas right-hand responding on the right response board produced an up-right/down-left mapping advantage. The failure to find a reversal of the eccentricity effect when the response board is placed behind the stimulus panel is inconsistent with the virtuallines hypothesis, but is consistent with both the salientfeatures and the end-state comfort hypothesis.

\section{EXPERIMENT 2}

In Experiment 2, we tested the conditions that reverse the eccentricity effect according to the end-state comfort hypothesis, namely when the $\mathrm{S}-\mathrm{R}$ set is reversed. Instead of pressing a left and a right key in response to top and bottom stimuli, subjects performed upward and downward responses (responses toward and away from the body) to left and right stimuli. Hand posture relative to the response board and the body remained the same as in Experiment 1. The hand was held at eccentric locations, at a straight angle to the fronto-parallel plane (Figure 3). 



Response board location
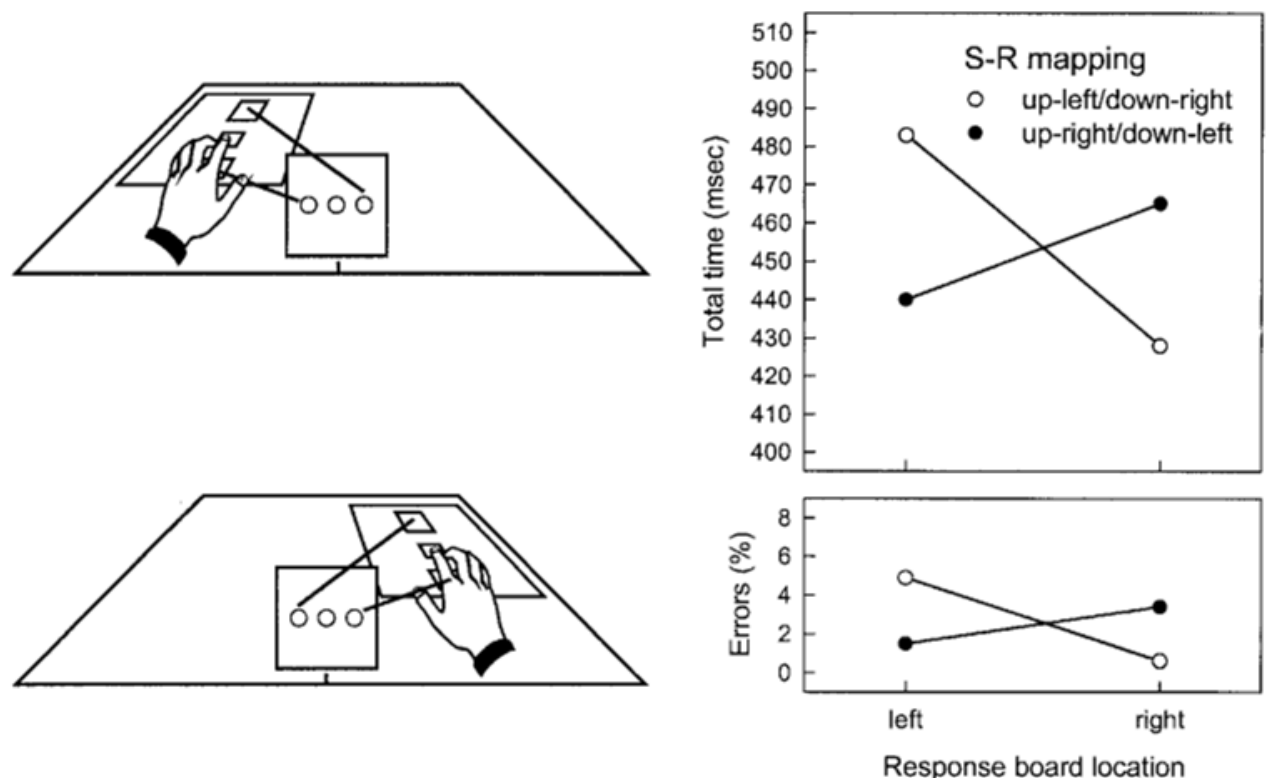

Figure 3. Left panels: The stimulus-response (S-R) arrangements investigated in Experiment 2, separately for the left and right response board location and the response board located in front of or behind the stimulus panel. Lines connecting stimulus and response locations indicate the preferred $S-R$ mapping. Right panels: The reversed eccentricity effect obtained in Experiment 2, separately for the response board located in front of or behind the stimulus panel. Total times and errors are presented as a function of S-R mapping and response board location.

For this reason, the left as well as the right response board should be mentally rotated inward. Accordingly, the clockwise rotation of the left response board maps "up" on "right" and "down" on "left," and the counterclockwise rotation of the right response board maps "up" on "left" and "down" on "right." The end-state comfort hypothesis thus predicts that Experiment 2 should yield an up-right/down-left mapping advantage for responding on the left response board, and an up-left/down-right mapping advantage for responding on the right response board (note that now the vertical first term indicates the response and the horizontal second term indicates the stimulus). Evidence for a reversal of the eccentricity effect when the S-R set is reversed was reported by Michaels (1989, Experiment 2). However, the effects were comparably small, especially for left-hand responding in left 
hemispace. In order to obtain additional evidence, we ran a replication of Michaels's (1989, Experiment 2) experiment with our experimental setup.

As currently formulated, the salient-features hypothesis does not make a clear prediction about how placement of the response board in left or right hemispace should affect performance with a reversed S-R set. Weeks et al. (1995) assumed that "the response associated with the hemispace in which the response set is placed becomes the salient member of the response set" (p. 372) and, thus, restricted the impact of the response board position to the coding of horizontally oriented responses. To predict on the basis of the salient-features hypothesis that placement of the response board in left or right hemispace will have the same effect on preference patterns for left and right stimuli mapped to upward and downward responses requires the assumption that hemispace of the response board also influences coding of the stimulus locations. According to such a modified salient-features hypothesis, Experiment 2 should replicate the original eccentricity effect because the eccentric response locations of left and right are maintained. When responding takes place in left hemispace, the "left" and "right" stimulus positions become salient and nonsalient, respectively, and, therefore, match the salient top and nonsalient bottom response locations, respectively. This yields a preference for upleft/down-right mapping. In turn, when responding takes place in right hemispace, "right" and "left" stimulus positions become salient and nonsalient, should therefore match the salient top and nonsalient bottom response locations, respectively, and cause an up-right/down-left mapping preference.

As shown in Figure 3, we ran two conditions again: one in which the response board was placed in front of the stimulus panel and one in which the response panel was placed behind the stimulus panel. Note that this manipulation was irrelevant for the predictions under test, but provided an additional test of the (already refuted) virtuallines hypothesis, which would predict an opposite pattern for the two conditions depicted in Figure 3.

\section{Method}

Subjects. Eight female and 8 male subjects (15 right-handed and 1 ambidextrous by self-report) were paid to participate in the experiment. Their mean age was 26.3 (range $=20-41$ ). All subjects had normal or corrected-to-normal acuity.

Apparatus, S-R Set, and Procedure. Experiment 2 was a replication of Experiment 1 with one change, the orientation of the stimulus and response set. In this experiment, subjects responded to left and right stimuli by pressing a response key located behind (upper key) and in front of (lower key) the central home key. To achieve these new locations, the wooden board of the stimulus panel and the response board were turned $90^{\circ}$.

\section{Results}

ANOVAs were conducted on TT and error data, with S-R arrangement (response panel in front of and behind the stimulus panel) serving as the between-subjects variable, and S-R mapping (up-left/down-right vs. upright/down-left), response board location (left vs. right), and response location (up vs. down) serving as the withinsubjects variables. The means of RTs, MTs, TTs, and errors are presented in Table 2.

Total times. The main effect of response location was significant $\left[F(1,14)=69.09, M S_{\mathrm{e}}=698.66, p<.001\right]$, indicating that downward responses were faster $(428 \mathrm{msec})$ than upward responses $(468 \mathrm{msec})$. The mapping $\times$ response board location interaction was also reliable $\left[F(1,14)=76.52, M S_{\mathrm{e}}=1,170.15, p<.001\right]$. Responding on a left response board was faster with up-right/ down-left mapping (426 msec) than with up-left/downright mapping $(482 \mathrm{msec})\left[F(1,14)=28.07, M S_{\mathrm{e}}=\right.$ $1,785.51, p<.001]$. The reversed effect occurred for responding on the right response board (467 vs. $417 \mathrm{msec}$ for up-right/down-left and up-left/down-right map-

Table 2

Mean Reaction Time (RT), Mean Movement Time (MT), Mean Total Time (TT, in Milliseconds), and Mean Error Rates (in Percentages) in Experiment 2 as a Function of Stimulus-Response Arrangement, Response Board Location, and Stimulus and Response Location

\begin{tabular}{|c|c|c|c|c|c|c|c|c|}
\hline \multirow[b]{3}{*}{ Response Location } & \multicolumn{4}{|c|}{ Response Board in Front of the Stimulus Panel } & \multicolumn{4}{|c|}{ Response Board Behind the Stimulus Panel } \\
\hline & \multicolumn{2}{|c|}{$\begin{array}{c}\text { Response Board } \\
\text { on Left } \\
\text { Stimulus Location }\end{array}$} & \multicolumn{2}{|c|}{$\begin{array}{c}\text { Response Board } \\
\text { on Right } \\
\text { Stimulus Location } \\
\end{array}$} & \multicolumn{2}{|c|}{$\begin{array}{c}\text { Response Board } \\
\text { on Left } \\
\text { Stimulus Location }\end{array}$} & \multicolumn{2}{|c|}{$\begin{array}{l}\text { Response Board } \\
\text { on Right } \\
\text { Stimulus Location }\end{array}$} \\
\hline & Left & Right & Left & Right & Left & Right & Left & Right \\
\hline \multicolumn{9}{|l|}{ Up } \\
\hline RT & 315 & 274 & 282 & 314 & 333 & 291 & 312 & 325 \\
\hline MT & 176 & 155 & 142 & 174 & 175 & 168 & 150 & 154 \\
\hline TT & 491 & 429 & 424 & 488 & 508 & 459 & 462 & 479 \\
\hline Errors & 4.4 & 0.3 & 0.3 & 3.1 & 4.4 & 2.1 & 0.6 & 4.0 \\
\hline \multicolumn{9}{|l|}{ Down } \\
\hline RT & 267 & 328 & 320 & 270 & 285 & 323 & 331 & 273 \\
\hline MT & 127 & 143 & 130 & 118 & 136 & 134 & 120 & 121 \\
\hline TT & 394 & 471 & 450 & 388 & 421 & 457 & 451 & 394 \\
\hline Errors & 0.3 & 3.7 & 3.2 & 0.6 & 0.9 & 5.3 & 2.7 & 0.6 \\
\hline
\end{tabular}


ping, respectively) $\left[F(1,14)=30.25, M S_{\mathrm{e}}=1,313.37\right.$, $p<.001]$. As indicated by a marginally significant mapping $\times$ response board location $\times S-R$ arrangement interaction $\left[F(1,14)=4.57, M S_{\mathrm{e}}=1,170.15, p=.051\right]$, the compatibility effect was larger with the response board in front of $(66 \mathrm{msec})$ than with that behind $(40 \mathrm{msec})$ the stimulus panel. In addition, the mapping $\times$ response board location $\times$ response location interaction reached significance $\left[F(1,14)=5.32, M S_{\mathrm{e}}=140.64, p<.05\right]$, indicating that the mapping $\times$ response board location interaction was more pronounced with downward $(58 \mathrm{msec})$ than with upward $(48 \mathrm{msec})$ responses.

Finally, a significant mapping $\times$ response location $\times$ $\mathrm{S}-\mathrm{R}$ arrangement interaction occurred $[F(1,14)=5.27$, $\left.M S_{\mathrm{e}}=491.76, p<.05\right]$. With the response board in front of the stimulus panel, the up-right/down-left mapping was $8 \mathrm{msec}$ faster than the up-left/down-right mapping for downward responses, whereas for upward responses there was no difference between the mappings (1 msec). With the response board behind the stimulus panel, a preference for the up-right/down-left mapping occurred for upward responses $(17 \mathrm{msec})$, whereas for downward responses the up-left/down-right mapping was faster $(11 \mathrm{msec})$. There is no ready explanation for this result. Actually, S-R mapping effects that occur independent of which hand is used to respond have been reported in the literature. However, they usually exhibit the pattern of an up-right/down-left mapping preference only (Adam et al., 1998; Weeks \& Proctor, 1990) and have not yet been shown to depend on the response location or response board position in the sagittal plane.

Errors. Only the mapping $\times$ response board location interaction was significant $\left[F(1,14)=18.03, M S_{\mathrm{e}}=\right.$ $17.49, p<.01]$. Responding on the left response board produced fewer errors with up-right/down-left mapping $(0.9 \%)$ than with up-left/down-right mapping $(4.5 \%)$ $\left[F(1,14)=11.97, M S_{\mathrm{e}}=16.92, p<.01\right]$. The reverse effect occurred for responding on the right response board (3.3\% vs. $0.5 \%$ for up-right/down-left and up-left/ down-right mapping, respectively) $[F(1,14)=16.08$, $\left.M S_{\mathrm{e}}=7.36, p<.01\right]$.

\section{Discussion}

Our findings accord well with the end-state comfort hypothesis. Changing the orientation of the stimulus and response set reversed the eccentricity effect. That is, responding on the left response board was characterized by an up-right/down-left mapping preference as opposed to an up-left/down-right mapping preference. Responding on the right response board was characterized by an up-left/down-right mapping preference as opposed to an up-right/down-left mapping preference.

With compatibility effects of 56 and $50 \mathrm{msec}$ for responding on the left and right response boards, respectively, we obtained a much larger reversal of the eccentricity effect than Michaels (1989) reported (approximately 8 and $20 \mathrm{msec}$ ). It turned out that the magnitude of our compatibility effects depended on response location and response board position in the sagittal plane. The compatibility effect was larger for downward responses than for upward responses (58 vs. $48 \mathrm{msec}$ ) and larger when the response board was placed in front of than behind the stimulus panel (66 vs. $40 \mathrm{msec}$ ). These findings are consistent with the end-state comfort hypothesis. In the conditions that yielded a smaller effect (upward responses and a response board further away from the body), the arm was more extended than in the conditions that yielded a larger effect (downward responses and a response board near the body). As mentioned earlier, this makes it more difficult to deviate from the fingertip-to-wrist axis. Therefore, the rotation preferences for each hand were less pronounced, which caused less pronounced compatibility effects.

The present results pose a problem for the salientfeatures hypothesis. First, the assumptions of the original salient-features hypothesis do not allow for clear predictions if a reversed S-R set is used. Second, a modified version that assumes that the response board position influences the coding of the stimulus dimension predicted an incorrect outcome, namely no reversal of the eccentricity effect.

Since the reversal of the eccentricity effect occurred regardless of the relative position of the stimulus and response panels in the sagittal plane, Experiment 2 provided further evidence against the virtual-lines hypothesis. Since this is the second disconfirmation of the virtual-lines hypothesis, the following experiments will continue to focus only on the salient-features and endstate comfort hypothesis.

\section{EXPERIMENT 3}

In Experiment 3, the predictions of another modified salient-features hypothesis were tested. The changes to the salient-features hypothesis concerned two of its assumptions. First, the location of the response board does not determine the saliency on the horizontal dimension, but rather the location of the device that contains the horizontally oriented objects. Second, the device's location is not defined in relation to the body midline but rather in relation to the other device.

On the basis of these new assumptions, the salientfeatures hypothesis correctly predicts the eccentricity effect of Experiment 1 and its reversal in Experiment 2. In Experiment 1, the response board utilized the horizontal dimension, but since it was located either to the left or to the right of the stimulus panel in left or right hemispace, its relative position coincided with its absolute position in hemispace. In Experiment 2, on the other hand, stimuli rather than responses were horizontally oriented. According to the reformulated assumptions, the placement of the stimulus panel relative to the response device was relevant in this experiment. Hence, for the condition in which the response board was located in left hemispace, the relative position of the stimulus panel was "right." This makes "right" the salient polar referent in the hori- 

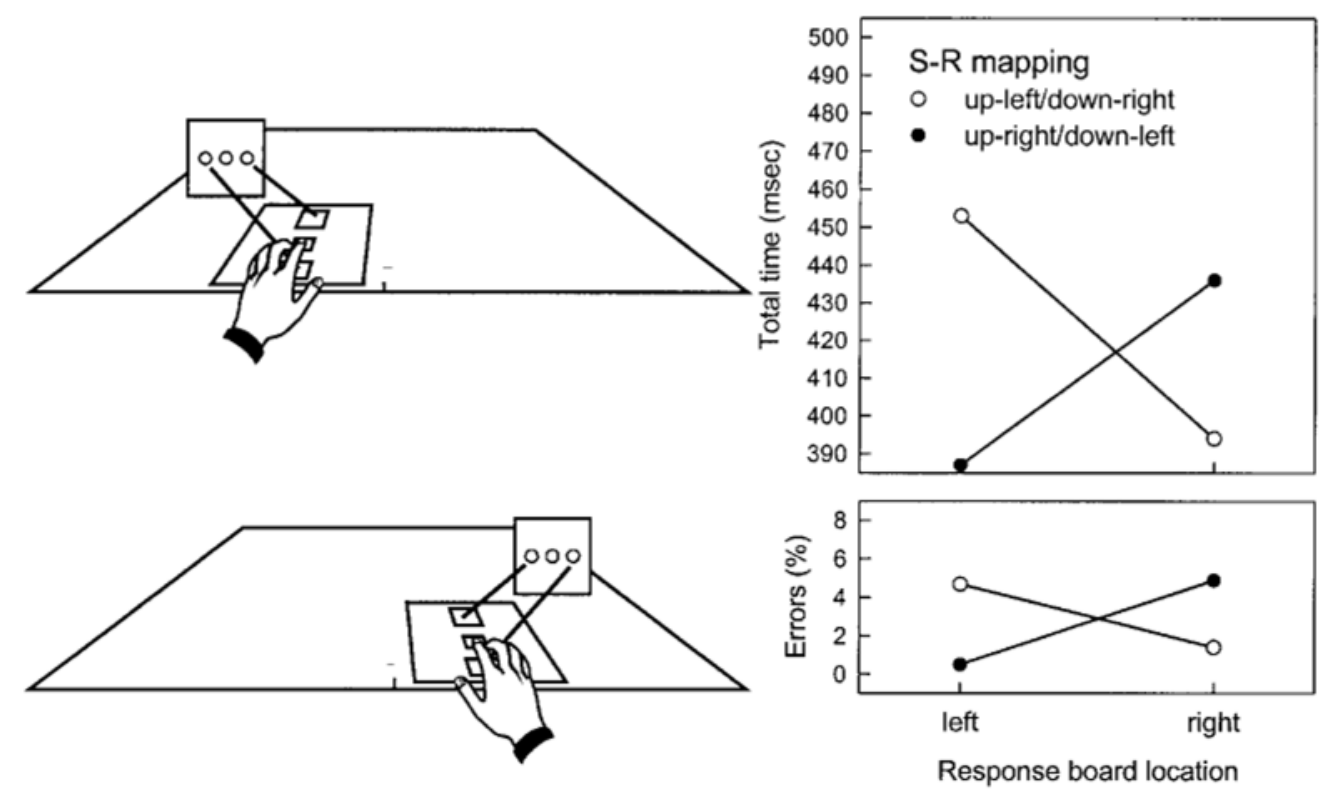

Figure 4. Left panel: The stimulus-response (S-R) arrangements investigated in Experiment 3, separately for the left and right response board locations. Lines connecting stimulus and response locations indicate the preferred S-R mapping. Right panel: The reversed eccentricity effect obtained in Experiment 3. Total times and errors are presented as a function of $S-R$ mapping and response board location.

zontal dimension and, therefore, evokes an up-right/ down-left mapping preference. For the conditionin which the response board was located in right hemispace, in turn, the relative position of the stimulus panel was "left." This makes "left" the salient polar referent in the horizontal dimension and, therefore, evokes an up-left/downright mapping preference. Consequently, Experiment 2 should have shown a reversal of the eccentricity effect found in Experiment 1.

In Experiment 3, this modified salient-features hypothesis was tested by placing the stimulus panel even more eccentrically (Figure 4). The panel was placed to the left of the left response board and to the right of the right response board (while the location of the response board was kept constant, that is, either to the left or to the right of the subject's body midline). According to the modified salient-features hypothesis, the reversal effect of Experiment 2 should disappear. When the stimulus panel is placed to the left of the left response board, it should evoke an up-left/down-right mapping advantage, whereas when it is placed to the right of the right response board, an up-right/down-left preference should materialize.

The end-state comfort hypothesis, on the other hand, predicts no such change. Since the position of the hand relative to the body and the response board remains the same, changing the relative position of the stimulus panel should have no effect. Responding with the left hand on the left response board should still favor a clockwise rotation, and responding with the right hand on the right response board should still favor a counterclockwise rotation, just as in Experiment 2. Accordingly, the eccentric- ity effect observed in Experiment 2 should also emerge in Experiment 3.

\section{Method}

Subjects. Six female and 2 male subjects (all right-handed by self-report) were paid to participate in the experiment. Their mean age was 26.8 (range $=21-44$ ). All subjects had normal or correctedto-normal acuity.

Apparatus, S-R Set, and Procedure. Experiment 3 was a replication of the "response-board-in-front-of-stimulus-panel" condition of Experiment 2. Yet, instead of the stimulus panel being placed on the body midline, it was placed to the leftmost and rightmost locations. Specifically, the stimulus panel was located $36 \mathrm{~cm}$ (from fixation light to center of the home key) to the left or right of

Table 3

Mean Reaction Time (RT), Mean Movement Time (MT), Mean Total Time (TT, in Milliseconds), and Mean Error Rates (in Percentages) in Experiment 3 as a Function of Response Board Location and Stimulus and Response Location

\begin{tabular}{|c|c|c|c|c|}
\hline \multirow[b]{2}{*}{ Response Location } & \multicolumn{2}{|c|}{$\begin{array}{l}\text { Response Board } \\
\text { on Left } \\
\text { Stimulus Location }\end{array}$} & \multicolumn{2}{|c|}{$\begin{array}{l}\text { Response Board } \\
\text { on Right } \\
\text { Stimulus Location }\end{array}$} \\
\hline & Left & Right & Left & Right \\
\hline \multicolumn{5}{|l|}{$\mathrm{Up}$} \\
\hline RT & 306 & 263 & 258 & 290 \\
\hline MT & 160 & 144 & 150 & 170 \\
\hline $\mathrm{TT}$ & 466 & 407 & 408 & 460 \\
\hline Errors & 5.7 & 0.3 & 2.8 & 6.0 \\
\hline \multicolumn{5}{|l|}{ Down } \\
\hline RT & 253 & 300 & 281 & 260 \\
\hline MT & 114 & 139 & 130 & 120 \\
\hline $\mathrm{TT}$ & 367 & 439 & 411 & 380 \\
\hline Errors & 0.6 & 3.6 & 3.8 & 0.0 \\
\hline
\end{tabular}


the response board, which, in turn, was located $30 \mathrm{~cm}$ (from center of home key to body midline) to the left or right of the subject (Figure 4, left panel). The viewing distance was approximately $85 \mathrm{~cm}$.

\section{Results}

ANOVAs were conducted on TT and error data, with S-R mapping (up-left/down-right vs. up-right/downleft), response board location (left vs. right), and response location (up vs. down) serving as the within-subjects variables. The means of RTs, MTs, TTs, and errors are presented in Table 3.

Total times. The main effect of response location was significant $\left[F(1,7)=6.36, M S_{\mathrm{e}}=3,269.90, p<.05\right]$, indicating that, again, downward responses were faster $(400 \mathrm{msec})$ than upward responses $(436 \mathrm{msec})$. In addition, the mapping $\times$ response board location reached significance $\left[F(1,7)=36.32, M S_{\mathrm{e}}=1,282.16, p<.01\right]$. Responding on a left response board was faster with upright/down-left mapping $(387 \mathrm{msec})$ than with up-left/ down-right mapping $(453 \mathrm{msec})\left[F(1,7)=17.88, M S_{\mathrm{e}}=\right.$ $1,943.12, p<.01]$, whereas the reversed effect occurred for responding on the right response board (436 vs. $394 \mathrm{msec}$ for the up-right/down-left and the up-left/down -right mapping, respectively) $\left[F(1,7)=6.69, M S_{\mathrm{e}}=\right.$ $2,110.87, p<.05$; Figure 4 , right panel].

Errors. The main effect of response location was significant $\left[F(1,7)=7.70, M S_{\mathrm{e}}=6.23, p<.05\right]$ : Downward responses were less error prone $(1.9 \%)$ than were upward responses $(3.7 \%)$. The mapping $\times$ response board location interaction was significant, too $[F(1,7)=$ $\left.30.18, M S_{\mathrm{e}}=7.73, p<.01\right]$. Responding on the left response board produced fewer errors with up-right/ down-left mapping $(0.5 \%)$ than with up-left/downright mapping $(4.7 \%)\left[F(1,7)=45.51, M S_{\mathrm{e}}=3.10, p<\right.$ $.001]$, whereas the reverse effect occurred for responding on the right response board (4.9\% vs. $1.4 \%$ for up-right/ down-left and up-left/down-right mapping, respectively) $\left[F(1,7)=9.85, M S_{\mathrm{e}}=9.58, p<.05\right]$.

\section{Discussion}

Experiment 3 replicated the results of Experiment 2that is, superior performance on the left and right response board with the up-right/down-left and up-left/ down-right mapping, respectively. Thus, changing the placement of the stimulus panel did not change the reversed eccentricity effect. This result supports the endstate comfort hypothesis and contradicts the modified salient-features hypothesis.

\section{EXPERIMENT 4}

According to the end-state comfort hypothesis, the key factor in orthogonal SRC effects that vary with response position, like the eccentricity effect, or with hand, like the effects reported by Lippa (1996), is relative hand posture. That is, it is assumed that differences in the end- state comfort of the response hand are critical for orthogonal SRC effect rather than differences in eccentric response position or hand identity. If this is correct, it should be possible to alter $\mathrm{S}-\mathrm{R}$ mapping preferences simply by manipulating hand posture, while keeping response position and hand constant. One possible test of this prediction is provided in Experiment 4, which replicated the design of vertically oriented stimuli and horizontally oriented responses of Experiment 1. Response position was kept constant by maintaining a position that is neutral along the horizontal plane. Hand was kept constant by investigating each hand under two conditions of hand posture.

Using the response board of the previous experiments in a centered placement, Lippa (1996) showed that different hand postures modulate orthogonal SRC effects in a way that is consistent with the end-state comfort hypothesis (Figure 1). A new experimental setting was therefore employed in Experiment 4. The computer mouse served as the response device. This allowed us to investigate hand postures that are difficult to create with the present response board. Specifically, subjects held the mouse with the index and middle finger resting on the left and right mouse button, while it was placed upright in the front of the subject in the fronto-parallel plane. There were two conditions of hand posture. In the "facing-theback-of-the-hand" (FB) condition, the front of the upright mouse and, thus, the back of the responding hand, faced the subject. In the "facing-the-palm" (FP) condition, the back of the mouse and, thus, the palm, faced the subject (Figure 5, left panel).

The predictions of the end-state comfort hypothesis are straightforward since particular rotation preferences are created, depending on the respective hand and posture of the hand. In the FB condition, holding the mouse causes a hand posture that makes it virtually impossible to rotate the left hand counterclockwise and the right hand clockwise in the sagittal plane. The rotation preference for the left and right hands would therefore be clockwise and counterclockwise, respectively. With left-hand responding, "left" is then mapped on "top" and "right" on "bottom," which should yield an up-left/down-right mapping preference. With right-hand responding, "left" is mapped on the "bottom," and "right" on "top," which should yield an up-right/down-left mapping preference. Since in the FP condition holding the mouse causes a hand posture that makes it almost impossible to rotate the left hand clockwise and the right hand counterclockwise in the sagittal plane, the opposite compatibility effects are predicted-an up-right/down-left mapping preference for the left hand and an up-left/down-right mapping preference for the right hand.

\section{Method}

Subjects. Twenty-four Indiana University undergraduates (16 females and 8 males) participated in individual sessions as part of 

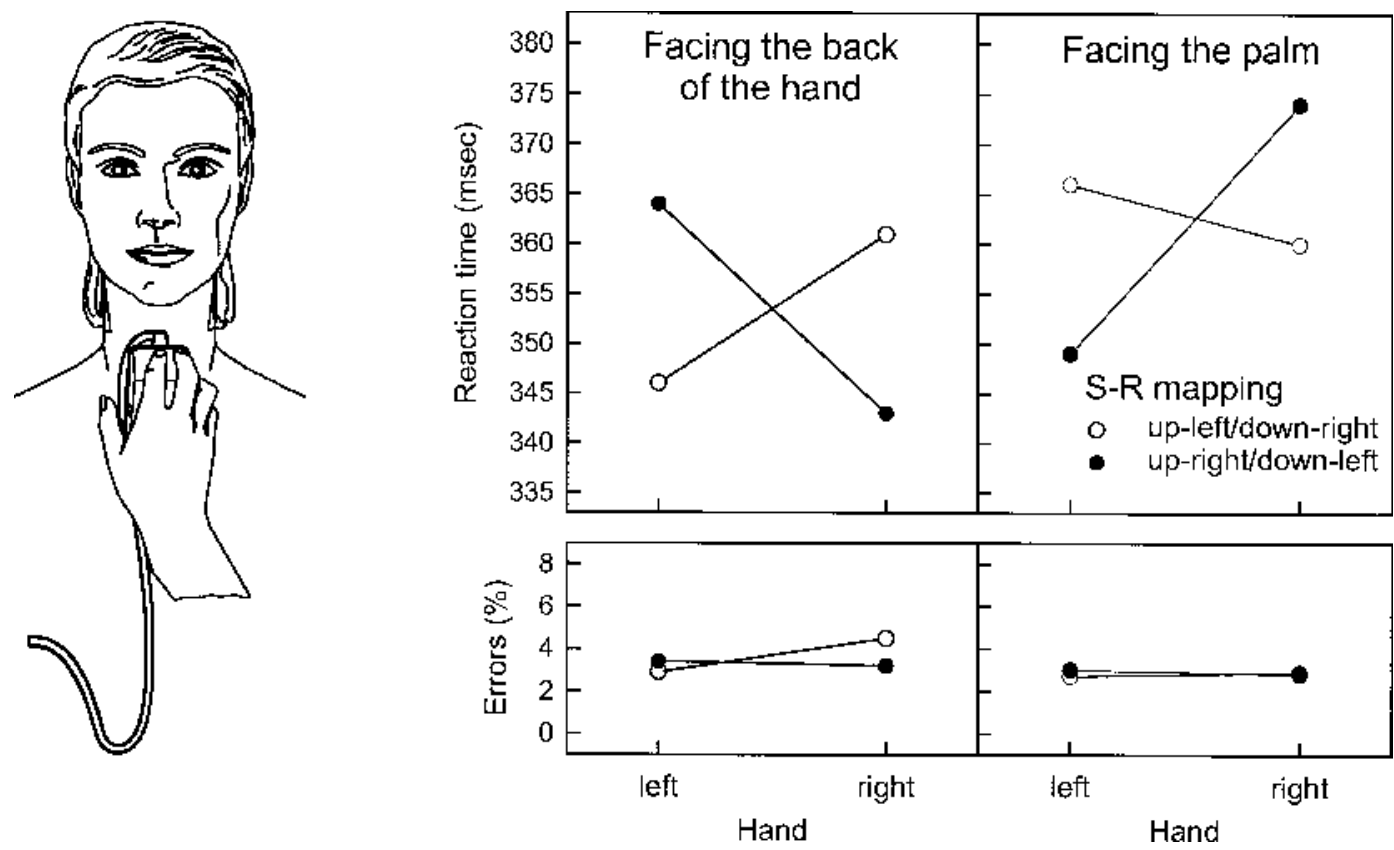

Figure 5. Left panel: The response setting used in Experiment 4 in the "facing the palm" condition. Right panel: The compatibility effects obtained in Experiment 4. Reaction times and errors are presented as a function of hand posture, stimulus-response (S-R) mapping, and responding hand.

a course requirement. Twenty-three were right-handed and 1 lefthanded by self-report, and their mean age was 20.2 years (range $=$ 18-37). They all had normal or corrected-to-normal acuity.

Apparatus and S-R Set. Stimulus presentation and data acquisition were controlled by a CompuAdd Express HPDT computer and Experimental Run Time System software (Beringer, 1998). The stimuli, standard uppercase X's $(0.3 \times 0.4 \mathrm{~cm})$ in black on a white background, were presented on a CompuAdd 51109 monitor. They appeared with their centers $1.5 \mathrm{~cm}$ above or below a central fixation mark (a standard plus sign).

Responses were made on a computer mouse with three buttons (400-dpi bus mouse, Model TX-2BHR). Only the left and the right buttons were used; the middle button was nonfunctional. The mouse was attached to a chinrest that was fixed at the table in front of the subject. The chinrest had the shape of an $\mathrm{H}$. The horizontal strut was $15 \mathrm{~cm}$ above the table (92 $\mathrm{cm}$ above the floor) and was $34 \mathrm{~cm}$ in length. In the center of the strut, there was a wooden block $(13.5 \times 2.5 \mathrm{~cm})$ around which Velcro was wrapped. The counterpart of the Velcro was on the back of the mouse, so that the mouse could be attached at the front of the strut (with the buttons facing the subject) or at the back of the strut (with the buttons point away from the subject). The distance between the back of the mouse and the computer screen was approximately $50 \mathrm{~cm}$.

Procedure. In the beginning of the experiment, subjects were told that they are going to respond with the computer mouse while maintaining a certain hand posture. The experimenter was present throughout the experiment and instructed and controlled hand posture before a new condition was started.

Subjects were seated at the table with their sagittal midline in line with the center of the mouse and the central fixation mark. In all conditions, they held the mouse with their index and middle finger on the buttons and the thumb and the ring and little finger at the sides. The variable of hand posture was manipulated between subjects. For half the subjects, the mouse was attached at the front of the chinrest with the buttons facing the subject. Subjects held the mouse by reaching out, so that they faced the back of their hand (FB condition). The distance between the mouse and the body was limited to approximately $20 \mathrm{~cm}$. The viewing distance was approximately $70 \mathrm{~cm}$. For the other subject group, the mouse was attached at the back of the chinrest with the buttons pointing away from the subject. Subjects held the mouse by reaching under the horizontal strut with the palm facing their body (FP condition). Subjects leaned against the strut, so that responding took place directly in front of the body. The viewing distance was approximately $50 \mathrm{~cm}$.

The subject's task was to press the left and right keys in response to top and bottom stimuli. In the instruction for the subjects and in the following description of the experimental conditions, "left" and "right" are defined in reference to the subject's sagittal midline. Thus, in the FB condition, the left and right keys coincided with the left and right mouse buttons, respectively, whereas in the FP condition, the left key was the right mouse button and the right key was the left mouse button.

Each subject completed four blocks in which the variables S-R mapping and responding hand were manipulated. In the first two blocks, subjects used one S-R mapping (e.g., up-left/down-right), and in the last two blocks, they used the other one (e.g., up-right/ down-left). In the first and third blocks, one hand was used to respond (e.g., the left hand), and in the second and fourth blocks, the other hand was used (e.g., the right hand). The order of S-R mapping and responding hand was balanced across subjects. Each block consisted of 90 trials: 10 practice trials and 80 test trials (40 for each stimulus location). To familiarize the subjects with the relevant $\mathrm{S}-\mathrm{R}$ mapping rule, additional training was given: 10 practice trials before the first and 20 practice trials before the second S-R assignment was tested.

Each trial began with presenting the central fixation mark for $1 \mathrm{sec}$. After a delay of $100 \mathrm{msec}$, the $\mathrm{X}$ was displayed randomly above or below the fixation mark. The stimulus remained visible until the subject responded or $1 \mathrm{sec}$ had passed (missing trial). Auditory feedback (a beep) was given for error, missing $(0.3 \%)$, and anticipation 
Table 4

Mean Reaction Time (RT, in Milliseconds) and Mean Error Rates (in Percentages) in Experiment 4 as a Function of Hand Posture, Responding Hand, and Stimulus and Response Location

\begin{tabular}{|c|c|c|c|c|c|c|c|c|}
\hline \multirow[b]{3}{*}{ Response Location } & \multicolumn{4}{|c|}{ Facing the Back of the Hand } & \multicolumn{4}{|c|}{ Facing the Palm } \\
\hline & \multicolumn{2}{|c|}{$\begin{array}{c}\text { Left Hand } \\
\text { Stimulus Location }\end{array}$} & \multicolumn{2}{|c|}{$\begin{array}{c}\text { Right Hand } \\
\text { Stimulus Location } \\
\end{array}$} & \multicolumn{2}{|c|}{$\begin{array}{c}\text { Left Hand } \\
\text { Stimulus Location }\end{array}$} & \multicolumn{2}{|c|}{$\begin{array}{c}\text { Right Hand } \\
\text { Stimulus Location } \\
\end{array}$} \\
\hline & Up & Down & Up & Down & Up & Down & $\mathrm{Up}$ & Down \\
\hline \multicolumn{9}{|l|}{ Left } \\
\hline RT & 347 & 359 & 371 & 351 & 359 & 336 & 368 & 367 \\
\hline Errors & 2.0 & 3.0 & 5.0 & 4.0 & 3.4 & 3.2 & 2.7 & 3.1 \\
\hline \multicolumn{9}{|l|}{ Right } \\
\hline RT & 368 & 345 & 335 & 351 & 362 & 372 & 382 & 351 \\
\hline Errors & 3.7 & 3.7 & 2.3 & 3.9 & 2.7 & 1.9 & 2.4 & 3.1 \\
\hline
\end{tabular}

(RT equal or below 120 msec: 0\%) trials, which were then repeated in the remainder of the block.

\section{Results}

ANOVAs were conducted on RT and error data, with hand posture (facing the back of the hand vs. facing the palm) as a between-subjects variable and S-R mapping (up-left/down-right vs. up-right/down-left), responding hand (left vs. right), and response location (left vs. right) as within-subjects variables. Mean RTs and error rates are presented in Table 4.

Reaction times. The relevant posture $\times \mathrm{S}-\mathrm{R}$ mapping $\times$ hand interaction was highly significant $[F(1,22)=$ $\left.16.65, M S_{\mathrm{e}}=804.10, p<.001\right]$. As Figure 5 shows, the data pattern confirms the predictions of the end-state comfort hypothesis. In the FB condition, left-hand responding is better with up-left/down-right mapping (346 msec) than with up-right/down-left mapping $(364 \mathrm{msec})\left[F(1,11)=2.16, M S_{\mathrm{e}}=1,788.45, p=.169\right]$, and right-hand responding is better with up-right/downleft mapping (343 msec) than with up-left/down-right mapping $(361 \mathrm{msec})\left[F(1,11)=2.38, M S_{\mathrm{e}}=1,627.92\right.$, $p=.151]$. In the FP condition, the effects reverse. Lefthand responding is better with up-right/down-left mapping (349 msec) than with up-left/down-right mapping $(366 \mathrm{msec})\left[F(1,11)=3.84, M S_{\mathrm{e}}=849.75, p=.076\right]$, and right-hand responding is better with up-left/downright mapping (360 $\mathrm{msec})$ than with up-right/down-left mapping $(374 \mathrm{msec})\left[F(1,11)=1.29, M S_{\mathrm{e}}=1,931.59\right.$, $p=.281]$.

Besides S-R compatibility effects, the analysis revealed a response-response compatibility effect, indicated by a reliable hand $\times$ response location interaction $[F(1,22)=$ $\left.5.34, M S_{\mathrm{e}}=1,002.88, p<.05\right]$. In left-hand conditions, left responses were performed faster $(350 \mathrm{msec})$ than right responses $(362 \mathrm{msec})$, whereas in right-hand conditions, right responses were performed faster $(355 \mathrm{msec})$ than left responses $(364 \mathrm{msec})$. In addition, the posture $\times$ response interaction was significant $[F(1,22)=7.31$, $\left.M S_{\mathrm{e}}=446.38, p<.05\right]$. In the FB condition, right responses were faster $(350 \mathrm{msec})$ than left responses (357 $\mathrm{msec})$, while in the FP condition the reverse effect occurred (367 and $358 \mathrm{msec}$ for right and left responses, respectively). There is no ready explanation for this particular result since it is difficult to see why posture should affect responses irrespective of the responding hand. Finally, a significant mapping $\times$ response location interaction was obtained $\left[F(1,22)=6.89, M S_{\mathrm{e}}=399.41, p<\right.$ $.05]$. There was an up-right/ down-left mapping preference for left responses (353 vs. $361 \mathrm{msec}$ ) and an upleft/down-right mapping preference for right responses ( 355 vs. $362 \mathrm{msec}$ ).

Errors. The only significant effect was the mapping $\times$ hand interaction $\left[F(1,22)=4.72, M S_{\mathrm{e}}=3.09, p<\right.$ $.05]$. It resulted from left-hand responses being less error prone than right-hand responses when the up-left/downright mapping applied. This mapping $\times$ hand interaction was not modulated by posture $(p>.20)$. The posture $X$ hand $\times$ response location interaction was marginally significant $\left[F(1,22)=3.62, M S_{\mathrm{e}}=9.81, p=.070\right]$. In the FB condition, left-hand responding yielded fewer errors for left than for right responses (2.5\% vs. 3.7\%), whereas right-hand responding yielded fewer errors for right than for left responses (3.1\% vs. $4.5 \%$ ). In the FP condition there was evidence for the reverse pattern; lefthand responding yielded fewer errors for right than for left responses $(2.3 \%$ vs. $3.3 \%$; errors for right-hand responding were almost the same for left [2.9\%] and right [2.8\%] responses). This data pattern suggests a compatibility effect of hand and anatomical finger. In the FB condition, the anatomical left and right fingers coincide with the left and right response keys, respectively. Hence congruency between hand and response location is equivalent to congruency between hand and anatomical finger. In the FP condition, however, the anatomical left finger pressed the right key and the anatomical right finger pressed the left key. Hence, fewer errors with incongruency between hand and response location mean better performance with congruency between hand and anatomical finger.

\section{Discussion}

Experiment 4 provided further evidence in favor of the end-state comfort hypothesis. If hand posture is manipulated so that the rotation preference for the left hand is clockwise and for the right hand counterclockwise 
(FB condition), left-hand responding is faster with up-left/down-right mapping and right-hand responding is faster with up-right/down-left mapping. If, in turn, hand posture suggests a counterclockwise rotation preference for the left hand and a clockwise rotation preference for the right hand (FP condition), the SRC effects reverse.

Experiment 4 shows that it is possible to alter mapping preferences for orthogonal stimuli and responses solely by manipulating relative hand posture. The present effects cannot be attributed to identity of hand because both hands performed better with up-right/downleft and up-left/down-right mapping, depending on posture condition. Position of the response device could not have contributed since it was kept constant. Variables that covary irrespective of hand posture with the observed effects are identity of the responding finger and identity of the mouse button. Responses with the middle finger or the left mouse button are faster for top stimuli and responses with the index finger or the right mouse button are faster for bottom stimuli. However, both factors could have produced the SRC effects only if subjects had coded the responses in an effector-centered or object-centered frame of reference. This is unlikely. When effector-centered and object-centered frames of reference are pitted against the subject's egocentric frame of reference, SRC effects have been shown to depend on the latter one (Ehrenstein et al., 1989; Wallace, 1971). Thus, in Experiment4, stimuli and responses may have been coded with reference to the subject's body-midline and hand posture determined whether right or left responses were cognitively mapped on top (or bottom) stimuli.

\section{GENERAL DISCUSSION}

The goal of the present study was to test predictions of the end-state comfort hypothesis, an account that explains orthogonal SRC effects that vary with hand or response position. In the first three experiments, we investigated the eccentricity effect, finding that when responding takes place in left hemispace, it is easier to assign top and bottom stimuli to left and right responses than to right and left responses, and when responding takes place in right hemispace, it is easier to assign top and bottom stimuli to right and left responses than to left and right responses.

Experiments 1 and 2 demonstrated that the eccentricity effect occurs regardless of the position of the response board relative to the position of the stimulus panel in the sagittal plane. Since this manipulation did not change response position in the horizontal plane or the rotation preferences of the left and right hand, this outcome is consistent with the salient-features and the end-state comfort hypotheses. However, the findings were inconsistent with the virtual-lines hypothesis because if the crossing and noncrossing of imagined interobject vectors were critical, a reversal of the eccentricity should have occurred.

Experiments 2 and 3 demonstrated that reversing the S-R set (i.e., using horizontally oriented stimuli and ver- tically oriented responses) reverses the eccentricity effect. Responding in left hemispace resulted in a preference for the up-right/down-left mapping, whereas responding in right hemispace resulted in a preference for upleft/down-right mapping. The reversal occurred regardless of the location of the stimulus panel relative to the response panel in the sagittal plane (Experiment 2) as well as the fronto-parallel plane (Experiment 3). This data pattern was predicted by the end-state comfort hypothesis because, if an inward rotation entails the most comfortable end-state posture for either hand, vertically oriented responses map onto horizontally oriented stimuli differently from the way horizontally oriented responses map onto vertically oriented stimuli (regardless of the position of the stimulus panel). The reversal of the eccentricity effect, however, was inconsistent with the salient-features hypothesis. Neither the original version nor modified versions were able to consistently predict the relevant salient polar referent and, thus, the direction of the eccentricity effect. Therefore, the applicability of the salient-features hypothesis to orthogonal SRC effects that vary with hand or response position is limited. Of course, this does not negate the fact that the salientfeatures coding principle accounts for the overall advantage of up-right/down-left mapping across a range of stimulus and response sets (Weeks \& Proctor, 1990; but see Adam et al., 1998) and for other phenomena (e.g., response precuing effects, Proctor \& Reeve, 1986).

Experiment 4 produced a new orthogonal SRC effect that was predicted by the end-state comfort hypothesis. If left and right buttonpresses are performed on a vertically oriented computer mouse in response to top and bottom stimuli, a clockwise rotation preference resulted in an up-left/down-right advantage. A counterclockwise rotation preference resulted in an up-right/down-left advantage. The fact that these effects occurred in the absence of eccentric response positions and regardless of hand questions the general applicability of accounts that favor the one or the other variable as determining this sort of orthogonal SRC effect (e.g., like the salient-features hypothesis).

To date, the end-state comfort hypothesis is the only account that provides a parsimonious and consistent explanation for the variation of orthogonal SRC effects with hand or response position. It accounts for all handdependent SRC effects reported and reviewed by Lippa (1996), explains the present experiments (Experiments 1, 2 , and 3 ) and previous findings on the eccentricity effect (Michaels \& Schilder, 1991, Experiment 1; Weeks et al., 1995, Experiment 1), and correctly predicts a new orthogonal SRC effect (Experiment 4).

The explanatory scope of the hypothesis is based on the assumption that not a single variable, but the interplay of several variables, evokes compatibility effects. Prior to the end-state comfort hypothesis, mainly "singlevariable" accounts had been discussed in the literature. These are helpful in explaining a particular data pattern, but fail when applied to a variety of experimental condi- 
tions. For example, Michaels's (1989; Michaels \& Schilder, 1991) finding that responding in the eccentric ipsilateral hemispace produces the eccentricity effect led her to assume that hand position is a critical variable. But hand position alone turned out to be insufficient; Weeks et al. (1995) have shown that the eccentricity effect also occurs when responding takes place in the contralateral hemispace with the hand held in a different position. Weeks et al.'s salient-features explanation of the eccentricity effect, instead, argues that response location is a critical variable. Again, this hypothesis is supported by part of the evidence, but fails to explain the reversal of the eccentricity effect when the S-R set is reversed (Experiments 2 and 3) and the occurrence of SRC effects that vary with hand when response location is not eccentric (Experiment 4; Bauer \& Miller, 1982; Lippa, 1996). A final single-variable account may be applied to the present data. One could argue that the outcomes of Experiments 1, 2, and 3 resulted from a movement preference of either hand to rotate inward. In all conditions the left hand preferred to move clockwise and the right hand preferred to move counterclockwise. However, this interpretation is not consistent with Bauer and Miller's (1982) and Lippa's (1996) findings and, in part, the results of Experiment 4 that demonstrated outward rotation preferences by either hand. In sum, there is no doubt that individual results can be explained by other (single-variable) accounts. However, the end-state comfort hypothesis provides for all of these different results a unitary explanation since the entire action scenario is taken into account. Orthogonal SRC effects that vary with hand or response position are not attributed to hand or response location alone, but are attributed to the interplay of these variables: It is hand posture relative to the response device and the body that constraints imagined hand movements and response transformations, thereby evoking compatibility effects.

The notion of cognitive spatial transformations has usually found application in the area of mental rotation tasks-that is, in tasks where subjects are explicitly required to transform objects or spatial relations to solve a problem. Therefore, the question arises whether the transformations performed in the current compatibility task are also strategic in nature or are automatic. Since transformations occur in spatially congruent and spatially incongruent settings, it seems likely that theses processes are automatic. If subjects utilize mental transformations strategically, they should always aim at a spatial alignment of the stimulus and response rather than a spatial nonalignment. Since this was not the case, it rather appears that the coding of stimulus and response dimensions is fully determined by the relative posture of the hand. Once the hand is placed in a certain position relative to the response device and the body, there is only one interpretation of the setting, irrespective of whether it yields spatial correspondence or not.

This notion of an action-dependent interpretation of the $\mathrm{S}-\mathrm{R}$ arrangement is not only held by the end-state com- fort hypothesis, but also by the account of S-R compatibility proposed by Michaels and colleagues (Michaels, 1989; Michaels \& Schilder, 1991; Michaels \& Stins, 1997). They suggested that the phenomenon of S-R compatibility might be explained with reference to the ecological approach to perception and action. This approach assumes that the "information that modulates activity is itself modulated by the activity," in particular, "that both the nature and the state of the action system provide constraints on which stimulus patterns will regulate it" (Michaels \& Schilder, 1991, p. 342). This idea captures the essence of the reasoning behind the end-state comfort hypothesis. Relative hand posture evokes a particular interpretation of the response dimension, which first establishes the mutual compatibility of the stimulus and response. However, the end-state comfort hypothesis not only rephrases these previous ideas, but also develops them further and specifies them. For example, Michaels (1989) and Michaels and Schilder (1991) assumed that the state of the motor system itself (i.e., muscle activity) conditions S-R compatibility. Accordingly, they tried to determine the influence of hand position and posture separately. In contrast, the end-state comfort hypothesis posits that action possibilities resulting from the state of the motor system are critical. Hand posture itself is meaningless, unless it is regarded as part of an action scenario. Muscle activity in the hand and arm conditions SRC effects only because in a particular arrangement of stimuli, responses, and the body, it suggests that, for example, a clockwise rotation is more comfortable than a counterclockwise rotation. The end-state comfort hypothesis is also a valuable addition because it allows for specific predictions. Michaels (1989) and Michaels and Schilder (1991) showed only that the variable hand modulates orthogonal SRC effects, but they did not specify in what respect. Instead, by posing the problem in terms of which actions are easy to perform and which are not easy to perform, it is possible to predict the absence and presence as well as the direction of hand-dependent SRC effects.

In sum, the end-state comfort hypothesis contributes to our understanding of S-R compatibility in several respects. First, it provides a unitary explanation for a variety of orthogonal SRC effects that vary with hand or response position. Second, in so doing, it conforms with assumptions postulated by current theories of S-R compatibility. Most of these theories state that for SRC effects to occur, overlap between the $\mathrm{S}-\mathrm{R}$ dimensions is required (see, e.g., Hommel \& Prinz, 1997). By assuming that physically orthogonal stimuli and responses are cognitively represented on a common spatial dimension, the present orthogonalSRC effects meet this criterion and are thus open to a conventional explanation. In addition, the claim that compatibility of stimuli and responses emerges only because of an action-dependent interpretation of the $\mathrm{S}-\mathrm{R}$ arrangement is consistent with the idea of the ecological SRC approach that action sets up perception (Michaels, 1989; Michaels \& Schilder, 1991; Michaels \& Stins, 1997). Hence, third, the end-state com- 
fort hypothesis integrates assumptions and ideas that used to be pursued independently and may give rise to a broader understanding of S-R compatibility.

\section{REFERENCES}

Adam, J. J., Boon, B., PaAs, F. G. W. C., \& Umiltà, C. (1998). The up-right/down-left advantage for vertically oriented stimuli and horizontally oriented responses: A dual-strategy hypothesis. Journal of Experimental Psychology: Human Perception \& Performance, 24, 1582-1595.

BAuer, D. W., \& Miller, J. (1982). Stimulus-response compatibility and the motor system. Quarterly Journal of Experimental Psychology, 34A, 367-380.

BERINGER, J. (1998). Experimental run time system [Computer program]. Frankfurt: BeriSoft.

Bradshaw, J. L., Bradshaw, J. A., \& Nettleton, N. C. (1990). Abduction, adduction and hand differences in simple and serial movements. Neuropsychologia, 28, 917-931.

Brebner, J., Shephard, M., \& Cairney, P. (1972). Spatial relationships and S-R compatibility. Acta Psychologica, 36, 1-15.

Chase, W. G., \& Clark, H. H. (1971). Semantics in the perception of verticality. British Journal of Psychology, 62, 311-326.

Cooper, L. A., \& Shepard, R N. (1975). Mental transformations in the identification of left and right hands. Journal of Experimental Psychology: Human Perception \& Performance, 1, 48-56.

Cotton, B., Tzeng, O. J. L., \& Hardyck, C. (1977). A response instruction by visual-field interaction: S-R compatibility effect or ? Bulletin of the Psychonomic Society, 10, 475-477.

Cotton, B., Tzeng, O. J. L., \& Hardyck, C. (1980). Role of cerebral hemispheric processing in the visual half-field stimulus-response compatibility effect. Journal of Experimental Psychology: Human Perception \& Performance, 6, 13-23.

EASTON, R. D., \& Sholl, M. J. (1995). Object-array structure, frames of reference, and retrieval of spatial knowledge. Journal of Experimental Psychology: Learning, Memory, \& Cognition, 21, 483-500.

Ehrenstein, W. H., Schroeder-Heister, P., \& Heister, G. (1989). Spatial S-R compatibility with orthogonal stimulus-response relationship. Perception \& Psychophysics, 45, 215-220.

FitTs, P. M., \& Deininger, R. L. (1954). S-R compatibility: Correspondence among paired elements within stimulus and response codes. Journal of Experimental Psychology, 48, 483-492.

Hommel, B. (1997). Toward an action-concept model of stimulusresponse compatibility. In B. Hommel \& W. Prinz (Eds.), Theoretical issues in stimulus-response compatibility (pp. 281-320). Amsterdam: Elsevier.

Hommel, B., \& LipPA, Y. (1995). S-R compatibility due to contextdependent spatial stimulus coding. Psychonomic Bulletin \& Review, 2, 370-374.

Hommel, B., \& Prinz, W. (1997). Theoretical issues in stimulusresponse compatibility. Amsterdam: Elsevier.

Kornblum, S., Hasbrouce, T., \& Osman, A. (1990). Dimensional overlap: Cognitive basis for stimulus-response compatibility-A model and taxonomy. Psychological Review, 97, 253-270.

Kornblum, S., \& LeE, J. W. (1995). Stimulus-response compatibility with relevant and irrelevant stimulus dimensions that do and do not overlap with the response. Journal of Experimental Psychology: Human Perception \& Performance, 21, 855-875.

LeONARD, J. A. (1959). Tactual choice reactions: I. Quarterly Journal of Experimental Psychology, 11, 76-83.

LIPPA, Y. (1996). A referential-coding explanation for compatibility effects of physically orthogonal stimulus and response dimensions. Quarterly Journal of Experimental Psychology, 49A, 950-971.

Michaels, C. F. (1989). S-R compatibility depend on eccentricity of responding hand. Quarterly Journal of Experimental Psychology, 41A, 263-272.

Michaels, C. F., \& Schilder, S. (1991). Stimulus-response compatibilities between vertically oriented stimuli and horizontally oriented responses: The effects of hand position and posture. Perception \& Psychophysics, 49, 342-348.

Michaels, C. F., \& Stins, J. F. (1997). An ecological approach to S-R compatibility. In B. Hommel \& W. Prinz (Eds.), Theoretical issues in stimulus-response compatibility (pp.333-360). Amsterdam: Elsevier.

PARSONS, L. M. (1987a). Imagined spatial transformation of one's body. Journal of Experimental Psychology: General, 116, 172-191.

PARSONS, L. M. (1987b). Imagined spatial transformations of one's hands and feet. Cognitive Psychology, 19, 178-241.

PArsons, L. M. (1994). Temporal and kinematic properties of motor behavior reflected in mentally simulated action. Journal of Experimental Psychology: Human Perception \& Performance, 20, 709-730.

Proctor, R. W., \& Reeve, T. G. (1986). Salient-feature coding operations in spatial precuing tasks. Journal of Experimental Psychology: Human Perception \& Performance, 12, 277-285.

Proctor, R. W., \& Reeve, T. G. (1990). Stimulus-response compatibility. Amsterdam: Elsevier.

Proctor, R. W., Reeve, T. G., Weeks, D. J., Campbell, K. C., \& DORNIER, L. (1997). Translating between orthogonally oriented stimulus and response arrays in four-choice reaction tasks. Canadian Journal of Experimental Psychology, 51, 85-97.

Proctor, R. W., \& WANG, H. (1997). Set- and element-level stimulusresponse compatibility effects for different manual response sets. Journal of Motor Behavior, 29, 351-365.

RIDDERINKHOF, K. R. (1993). Interference from irrelevant information. Unpublished doctoral dissertation, University of Amsterdam.

Rosenbaum, D. A., \& Jorgensen, M. J. (1992). Planning macroscopic aspects of manual control. Human Movement Science, 11, 61-69.

Rosenbaum, D. A., Marchak, F., Barnes, H. J., Vaughan, J., Slotta, J., \& Jorgensen, M. (1990). Constraints for action selection: Overhand vs. underhand grips. In M. Jeannerod (Ed.), Attention and performance XIII (pp. 321-342). Hillsdale, NJ: Erlbaum.

Rossetti, Y., Meckler, C., \& Prablanc, C. (1994). Is there an optimal arm posture? Deterioration of finger localization precision and comfort sensation in extreme arm-joint postures. Experimental Brain Research, 99, 131-136.

SexiYama, K. (1982). Kinesthetic aspects of mental representations in the identification of left and right hands. Perception \& Psychophysics, 32, 89-95.

Simon, J. R. \& Rudell, A. P. (1967). Auditory S-R compatibility: The effect of an irrelevant cue on information processing. Journal of Applied Psychology, 51, 300-304.

WALlace, R. J. (1971). S-R compatibility and the idea of a response code. Journal of Experimental Psychology, 88, 354-360.

WeEks, D. J., \& Proctor, R. W. (1990). Salient-features coding in the translation between orthogonal stimulus and response dimensions. Journal of Experimental Psychology: General, 119, 355-366.

Weeks, D. J., Proctor, R. W., \& BeyaK, B. (1995). Stimulus-response compatibility for vertically oriented stimuli and horizontally oriented responses: Evidence for spatial coding. Quarterly Journal of Experimental Psychology, 48A, 367-383.

\section{NOTES}

1. Since the end-state comfort hypothesis identifies constraints in movement of the hands as critical, it may appear similar to Bauer and Miller's (1982) movement-preference explanation for compatibility effects of orthogonal S-R dimensions. However, both accounts differ in their reasoning as well as explanatory power. Bauer and Miller assumed that orthogonal SRC effects occur because an implicit hand movement toward the stimulus in conjunction with an explicit hand movement required by the instruction results in a movement sequence that either matches or mismatches the rotation preference of the responding hand. For example, if a left stimulus must be responded to by a top response, the hand moves first to the left and then upward. This joint clockwise movement is assumed to be preferred by the left hand, while a joint counterclockwise movement (e.g., first right, then upward) is assumed to be preferred by the right hand. Since Bauer and Miller could not find speed differences between the left and right hands when investigating 
simple rotational movements, they assumed that the occurrence of preferences required the sequence of movements, where the first movement is elicited by the stimulus and the second movement is performed in accordance with the instruction. Thus, according to the movementpreference hypothesis, the stimulus and its position play a major role in creating movement preferences. According to the end-state comfort hypothesis, in contrast, movement preferences are solely determined by biomechanical constraints of the hand resulting from its posture relative to the response device and the body. In addition to these theoretical differences, the movement-preference hypothesis does not provide a vi- able explanation for the eccentricity effect. Up-left/down-right mapping yields a joint counterclockwise movement, which should be preferred by the right hand. The up-right/down-left mapping yields a joint clockwise movement, which should be preferred by the left hand. However, the eccentricity effect exhibits the opposite pattern-a better left and right hand performance for up-left/down-right and up-right/ down-left mapping, respectively.

(Manuscript received February 9, 1999; revision accepted for publication February 17, 2000.) 